\title{
Radio-sensitization of the murine osteosarcoma cell line LM8 with parthenolide, a natural inhibitor of NF-кB
}

\author{
KENJIRO SUGIYASU ${ }^{1}$, KATSUHIKO NANNO ${ }^{1}$, NORIYUKI TAMAI ${ }^{1}$, NOBUYUKI HASHIMOTO $^{1}$, \\ YUKI KISHIDA $^{2}$, HIDEKI YOSHIKAWA ${ }^{1}$ and AKIRA MYOUI ${ }^{1,3}$ \\ Departments of ${ }^{1}$ Orthopaedics and ${ }^{2}$ Kampo Medicine, Osaka University Graduate School of Medicine; \\ ${ }^{3}$ Medical Center for Translational Research, Osaka University Hospital, Suita, Osaka 565-0871, Japan
}

Received December 6, 2010; Accepted February 24, 2011

DOI: $10.3892 / \mathrm{ol} .2011 .277$

\begin{abstract}
Nuclear factor (NF)- $\mathrm{B}$ has been shown to be associated with cancer resistance to radiotherapy (RT), and is constitutively active in the murine osteosarcoma cell line, LM8. Parthenolide has been reported to show antitumor activity through inhibition of the NF- $\mathrm{B}$ pathway. In this study, we investigated the radio-sensitizing activity of parthenolide. We established Luc-LM8, a stable transfectant reporter construct of $\mathrm{NF}-\kappa \mathrm{B}$ transcriptional activity into LM8. Luc-LM8 maintained the malignancy observed with LM8. In vitro, Luc-LM8 cells were cultured with or without parthenolide treatment, irradiated, and subjected to cell viability and apoptosis assays. In vivo, to investigate whether parthenolide enhances radio-sensitivity of tumors, a tumor growth assay was conducted. Parthenolide enhanced the growth inhibitory effect of RT and induced the apoptosis of Luc-LM8 cells with RT in vitro. The in vivo tumor growth was significantly suppressed in the mice treated with parthenolide and RT. The present study suggests that parthenolide sensitizes Luc-LM8 cells to irradiation. Thus, parthenolide is a potential candidate for use as a potent radio-sensitizing drug for use in cancer RT.
\end{abstract}

\section{Introduction}

Osteosarcoma is the most common malignant bone tumor in young adults and children (1). Treatment of osteosarcoma is limited to chemotherapy followed by surgery, as these types of tumor remain poor candidates for radiotherapy due to their high resistance to irradiation (2). However, surgical removal of the tumor together with the surrounding normal tissue may seriously impair the affected site. Furthermore, it may be impossible to resect the tumor with a wide and oncologically safe margin.

Correspondence to: Dr Akira Myoui, Medical Center for Translational Research, Osaka University Hospital, 2-15 Yamada-Oka, Suita, Osaka 565-0871, Japan

E-mail: myoi@hp-mctr.med.osaka-u.ac.jp

Key words: parthenolide, nuclear factor- $\kappa \mathrm{B}$, radio-sensitization, osteosarcoma
X-ray irradiation is a widely used treatment modality that can control local malignant tumors without causing severe damage to adjacent normal tissue. Irradiation-induced DNA damage and double-strand breaks are lethal to cells when the damage cannot be repaired (3). The outcome of irradiation therapy is improved when a higher dose of irradiation can be applied. However, as the dose increases, the side effects and late complications resulting from exposure of the surrounding normal tissue to irradiation increase to an unacceptable level, limiting the usefulness of high doses of irradiation. Therefore, it is important to find agents that sensitize malignant tumor cells to RT, thereby minimizing radiation toxicity to surrounding organs and allowing for lower effective therapeutic doses.

Numerous mechanisms are involved in the development of radio-resistance in tumor cells, and one of the possible mechanisms is activation of the nuclear factor (NF)- $\kappa \mathrm{B}$ signaling pathway (4-6). NF- $\mathrm{NB}$ is a heterodimeric transcription factor that is induced in response to a variety of stress stimuli, such as exposure to ionizing radiation, and plays an important role in the regulation of cell survival, apoptosis and the cell cycle $(4,5,7)$. Inhibition of the NF- $\kappa \mathrm{B}$ signaling pathway is considered to be a potential therapeutic approach to enhance the effect of irradiation therapy (8).

Previously, it was shown that NF- $\kappa \mathrm{B}$ is constitutively active in LM8 (9), a highly metastatic subclone of the Dunn murine osteosarcoma cell line (10), which may be responsible for the intrinsic radio-resistance of LM8 cells.

Parthenolide is a sesquiterpene lactone that is responsible for the activities of the plant feverfew. It is a traditional folk remedy that has long been used for various inflammatory conditions in Europe (11). Several studies have proposed that the effect of parthenolide is due to the inhibition of $N F-\kappa B$ activity. Parthenolide has been shown to inhibit growth or induce apoptosis in a number of tumor cell lines (12-16). In addition, parthenolide has been reported to show antitumor activity through inhibition of $\mathrm{NF}-\kappa \mathrm{B}$ DNA binding and other mechanisms (17-20) in various in vivo models.

This study aimed to investigate the radio-sensitizing activity of parthenolide to Luc-LM8, a stable transfectant reporter construct of the $\mathrm{NF}-\kappa \mathrm{B}$ transcriptional activity into LM8, in vitro and in animal models by subcutaneous (s.c.) inoculation of Luc-LM8 cells. 


\section{Materials and methods}

Cell culture. The cloned murine osteosarcoma cell line LM8, which shows a high metastatic incidence to the lung after s.c. inoculation into mice, was cultured in DMEM containing $10 \%$ fetal bovine serum and a $1 \%$ penicillin/streptomycin mixture in an air incubator with $5 \% \mathrm{CO}_{2}$ at $37^{\circ} \mathrm{C}$. We established Luc-LM8, a stable transfectant with pNF-кB-Luc (Stratagene, La Jolla, CA, USA) 5 times tandem repeats of the consensus sequence of NF- $\mathrm{kB}$ binding site fixed with the luciferase gene into LM8, for evaluation of NF- $\mathrm{kB}$ transcriptional activity by luciferase reporter assay in vitro and in vivo. LM8 cells were transfected by Lipofectamine 2000 reagent (Invitrogen, Carlsbad, CA, USA) with pNF-kB-Luc and pc-DNA3.1, and these clones were placed for 3 weeks in culture medium containing $0.5 \mathrm{mg} / \mathrm{ml} \mathrm{G} 418$ (Gibco-BRL, Gaithersburg, MD, USA). G418-resistant clones were cultured in medium with $10 \mathrm{ng} / \mathrm{ml} \mathrm{TNF}-\alpha$ (R\&D, Minneapolis, MN, USA) for $3 \mathrm{~h}$ and selected by quantifying luciferase activities using the SingleLuciferase assay (Promega, Madison, WI, USA) to identify a stable transfectant.

Animals. C3H male mice (age, 5 weeks) were purchased from Japan Oriental Yeast Co., Ltd. (Tokyo, Japan) for in vivo tumor growth assay. The mice were housed under specific pathogenfree conditions with a 12-h light and dark cycle. The housing care rules and experimental protocols were approved by the Animal Care and Use Committee of Osaka University.

Tumorigenicity and metastatic potential. Luc-LM8 was investigated to determine whether it could form a tumor in vivo. Its metastatic potential to the lung as compared to LM8 was also investigated. Luc-LM8 cells $\left(1 \times 10^{6}\right)$ were suspended in $100 \mu 1$ PBS and inoculated s.c. into the right thigh of the mice. Mice were examined for s.c. tumor formation twice a week and sacrificed at 4 weeks after cell inoculation for histological examination of lung metastasis.

In vitro $N F-\kappa B$ transcriptional activity assay. Luc-LM8 cells $\left(1 \times 10^{5}\right)$ were incubated in 6-well plates at various concentrations $(0,0.5,1.0$ and $2.0 \mu \mathrm{g} / \mathrm{ml})$ of parthenolide (Sigma-Aldrich, St. Louis, MO, USA) for $24 \mathrm{~h}$, and luciferase activities were quantified using the Single-Luciferase assay system and a luminometer. Total protein per sample was determined using the BioRad protein assay (BioRad Laboratories, Hercules, CA, USA), and luciferase activity was expressed as relative light units $(\mathrm{RLU}) / \mathrm{mg}$ total protein.

Cell proliferation assay. Cell proliferation was evaluated using the WST-1 assay (Takara Bio, Otsu, Japan). Luc-LM8 cells $\left(1 \times 10^{3}, 96\right.$-well plates) were incubated in $100 \mu \mathrm{l}$ culturing medium with parthenolide ( 0 and $1.0 \mu \mathrm{g} / \mathrm{ml})$ for $24 \mathrm{~h}$, and then irradiated with 0, 2, 4 and $6 \mathrm{~Gy}, 180 \mathrm{kVp} \mathrm{X}$-rays. At $72 \mathrm{~h}$ after irradiation, parthenolide-containing medium was replaced with $110 \mu \mathrm{l}$ of that containing WST-1 solution (10 $\mu \mathrm{l}$ of WST-1 solution and $100 \mu \mathrm{l}$ of culture medium), and $3 \mathrm{~h}$ later the absorbance was determined at $450 \mathrm{~nm}$ with a reference wavelength of $620 \mathrm{~nm}$ using a multi-spectrophotometer (Viento, Dainippon Sumitomo Pharma, Osaka, Japan). Relative cell viability was represented as the ratio of the absorbance of

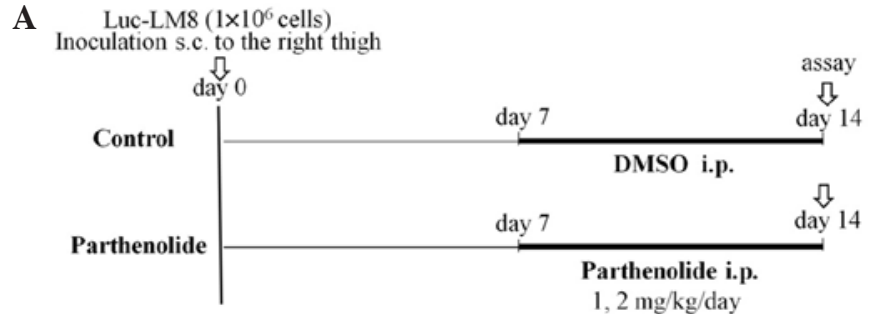

B

Luc-LM8 $\left(1 \times 10^{6}\right.$ cells $)$

Inoculation s.c. to the right thigh

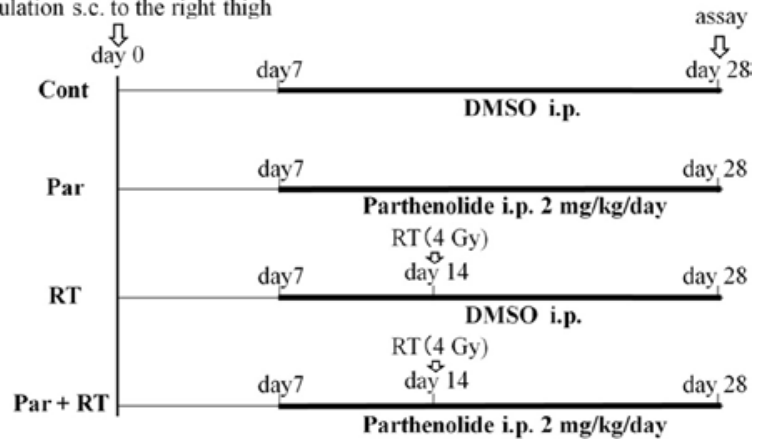

Figure 1. In vivo experimental protocols. (A) Mice were inoculated subcutaneously (s.c.) with Luc-LM8 cells $\left(1 \times 10^{6}\right)$ and divided into three groups ( $n=6$, each). Parthenolide was injected intraperitoneally (i.p.) at a dosage of 1 and $2 \mathrm{mg} / \mathrm{kg}$ daily from day 7 to 14 . The mice were sacrificed on day 14, and each primary tumor was subjected to tissue homogenate-based luciferase assay. (B) Luc-LM8 cells $\left(1 \times 10^{6}\right)$ were inoculated s.c. into the right thigh of 18 mice. Mice were divided into four groups: Par (parthenolide alone), RT (irradiation alone), Par+RT and control ( $n=4-5$ per group). The control group was injected i.p. with a vehicle daily starting from day 7, when tumor establishment was usually identified. Parthenolide was injected i.p. at a dosage of $2 \mathrm{mg} / \mathrm{kg}$ daily from day 7 in the Par and Par+RT groups. Irradiation with 4 Gy was administered to primary tumors on day 14 in the RT and Par+RT groups. The mice were sacrificed on day 28 , and primary tumors were collected for tumor size and histological evaluation by H\&E staining.

each experimental group vs. mean absorbance of the control (no parthenolide and no irradiation treatment) group, which was standardized as $100 \%$.

Apoptosis detection assay. Cell apoptosis was measured using the TACS Annexin V-FITC Apoptosis Detection kit $(R \& D)$. Luc-LM8 cells $\left(1 \times 10^{4}, 12\right.$-well plate) were incubated with parthenolide ( 0 and $1.0 \mu \mathrm{g} / \mathrm{ml}$ ) for $24 \mathrm{~h}$ and irradiated with 0,2 and $8 \mathrm{~Gy}, 180 \mathrm{kVp}$ X-rays. At $48 \mathrm{~h}$ after irradiation, cells were collected and centrifuged at $500 \mathrm{x} \mathrm{g}$ for $5 \mathrm{~min}$ at room temperature. Cells were washed by resuspending in $1 \mathrm{X}$ phosphate-buffered saline and pelleted by repeat centrifugation. Cells were then gently resuspended in $100 \mu$ l Annexin V incubation reagent and incubated in the dark for $15 \mathrm{~min}$. Following incubation, $400 \mu \mathrm{l} 1 \mathrm{X}$ binding buffer was added to each sample and the degree of apoptosis was assessed by the FACSCaliber ${ }^{\circledR}$ flow cytometer (Becton-Dickinson Immunocytometry Systems, San Jose, CA, USA).

Tumor homogenate-based $N F-\kappa B$ transcriptional activity assay. To investigate whether the NF- $\mathrm{BB}$ transcriptional activity in Luc-LM8 cells was inhibited by parthenolide in vivo, mice were inoculated s.c. with Luc-LM8 cells $\left(1 \times 10^{6}\right)$ and divided into three groups ( $\mathrm{n}=6$ in each group). The control group was injected intraperitoneally (i.p.) with a vehicle every day starting from day 7 to 14 . Parthenolide was injected i.p. 
A

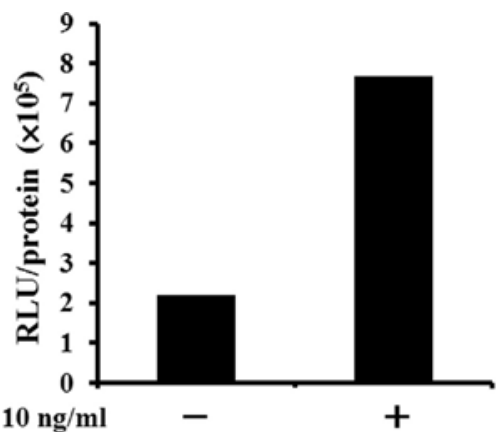

B

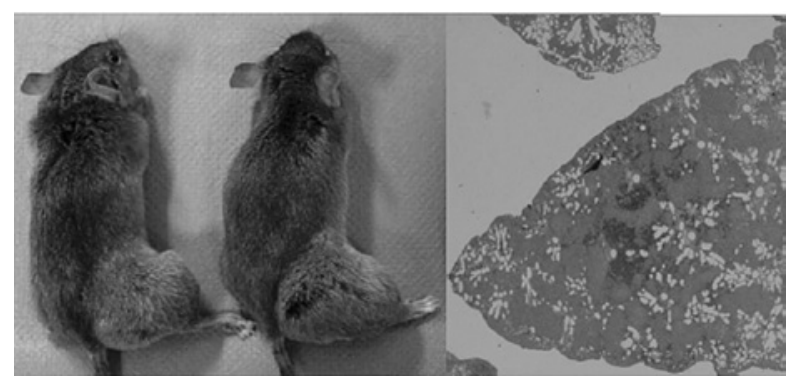

C

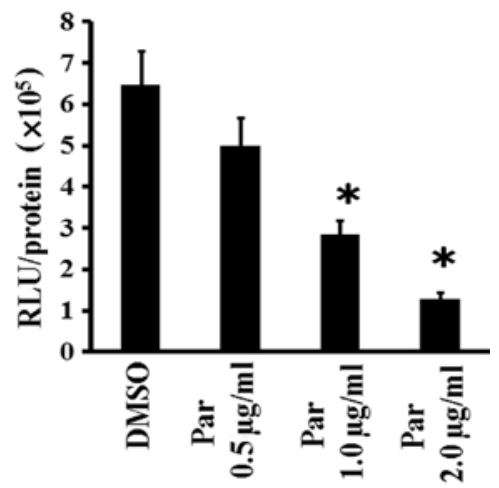

Figure 2. Establishment and characterization of the Luc-LM8 cell line. (A) In vitro $\mathrm{NF}-\kappa \mathrm{B}$ transcription activity stimulated by TNF- $\alpha$. Luc-LM8 cells were cultured in medium with $10 \mathrm{ng} / \mathrm{ml} \mathrm{TNF- \alpha}$ for $3 \mathrm{~h}$, and NF- $\kappa \mathrm{B}$ activity was determined by luciferase assay. Representative data of RLU/ protein are shown. A clear increase in NF- $\mathrm{NB}$ activity by TNF- $\alpha$ was found in Luc-LM8 cells. (B) Tumorigenicity and metastatic potential. Luc-LM8 cells $\left(1 \times 10^{6}\right)$ were suspended in $100 \mu$ l PBS and inoculated s.c. into the right thigh of mice. Luc-LM8 exhibited local tumor growth ability and metastatic potential to the lung. The primary tumors were noted on the right thigh where Luc-LM8 cells were inoculated subcutaneously on day 5 in all mice $(n=24)$, and metastases were found in lungs from all 6 histologically evaluated mice. (C) In vitro $\mathrm{NF}-\kappa \mathrm{B}$ transcription activity by parthenolide. Luc-LM8 cells $\left(1 \times 10^{5}\right)$ were incubated in 6 -well plates with various concentrations of parthenolide for $24 \mathrm{~h}$. Luciferase activities were quantified and expressed as RLU/protein (mean $\pm \mathrm{SD}, \mathrm{n}=3 ;{ }^{*} \mathrm{P}<0.05$ compared with $\mathrm{DMSO}$ ). The $\mathrm{NF}-\kappa \mathrm{B}$ transcription activity in Luc-LM8 cells was inhibited by parthenolide (Par) in a dose-dependent manner.

at a dosage of 1 and $2 \mathrm{mg} / \mathrm{kg}$ daily in the other two groups from day 7 to 14 . The mice were sacrificed on day 14 , and each primary tumor was collected and frozen in liquid nitrogen for tissue homogenate-based luciferase assay (21) (Fig. 1A). To extract luciferase protein, the tumor was placed in $300 \mu \mathrm{l}$ 1X RLB buffer (Promega, Southampton, UK) and homogenized using a Fast-Prep homogenizer (Thermo Fisher Scientific, Waltham, MA, USA) set to $60 \mathrm{~m} / \mathrm{sec}$ for $30 \mathrm{sec}$ followed by $15-\mathrm{min}$ incubation at room temperature. The supernatant was removed and transferred to a QIAshredder column (Qiagen, Crawley, UK) and centrifuged (2 min at
$16,000 \mathrm{x}$ g). Luciferase activity was measured in the supernatant. Luciferase activity was expressed as relative light units (RLU)/mg total protein.

Tumor growth assay. Luc-LM8 cells $\left(1 \times 10^{6}\right)$ were inoculated s.c. into the right thigh of 18 mice. To investigate whether parthenolide enhances the radio-sensitivity of tumors, mice were divided into four groups: Par (parthenolide alone), RT (irradiation alone), Par+RT and the control ( $n=4-5$ per group). The control group was injected i.p. with a vehicle every day starting from day 7, when tumor establishment was usually identified. Parthenolide was injected i.p. at a dosage of $2 \mathrm{mg} /$ $\mathrm{kg}$ daily from day 7 in the Par and Par+RT groups. Irradiation with 4 Gy was administered to primary tumors on day 14 in the RT and Par+RT groups. The mice were sacrificed on day 28, and primary tumors were collected for tumor size and histological evaluation by hematoxylin and eosin staining (Fig. 1B). Tumor size was evaluated by measuring the three dimensions of the excised tumor.

Statistical analysis. Data are presented as mean \pm SD for in vitro studies and the tumor growth model. Groups were compared by one-way analysis of variance, and individual groups were compared using the two-tailed Student's t-test. All analyses used a P-value with a 95\% confidence interval.

\section{Results}

Establishment of the Luc-LM8 cell line. We established 11

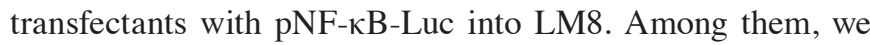
selected one cell line that was most similar to the wild-type LM8 cell line in terms of local tumorigenicity and a high metastatic potential to the lung after s.c. inoculation. We named this cell line Luc-LM8.

Relative luciferase activity corrected by protein concentration (RLU/protein) was increased $\sim 3$-fold when Luc-LM8 cells were cultured with TNF- $\alpha$ for $3 \mathrm{~h}$ compared with cells without TNF- $\alpha$ (Fig. 2A).

In the tumorigenicity and metastatic potential assay, Luc-LM8 cells exhibited local tumor-forming ability and spontaneous metastatic potential to the lung (Fig. 2B). The primary tumors at the right thigh were identified by day 5 in all mice $(n=24)$, and lung metastases were found in lungs from all 6 histologically evaluated mice. Results indicated that Luc-LM8, a clonal transfectant with pNF- $\kappa$ B-Luc into LM8, maintained the original malignancy potential of LM8.

To confirm that the transfected $\mathrm{pNF}-\kappa \mathrm{B}-\mathrm{Luc}$ functioned as a reporter construct of $\mathrm{NF}-\kappa \mathrm{B}$ transcriptional activity and that $\mathrm{NF}-\kappa \mathrm{B}$ activity of Luc-LM8 was regulated by parthenolide, Luc-LM8 cells were cultured in the presence of various concentrations of parthenolide and subjected to luciferase assay. RLU/ protein exhibited a high expression when the Luc-LM8 cells were cultured without the NF- $\mathrm{B}$ inhibitor. When treated with parthenolide, the RLU/protein value of each sample decreased inversely proportional to the dose of parthenolide (Fig. 2C). These results indicate that the luciferase activity described the $\mathrm{NF}-\kappa \mathrm{B}$ transcriptional activity in the Luc-LM8 cells and that $\mathrm{NF}-\kappa \mathrm{B}$ activity was inhibited by parthenolide in a dose-dependent manner in vitro. Therefore, all additional experiments were conducted using Luc-LM8 cells. 


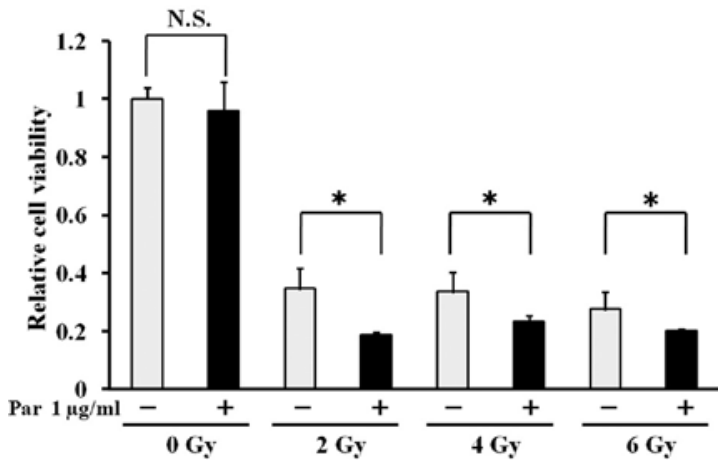

Figure 3. Parthenolide enhances irradiation-induced growth inhibition of Luc-LM8 cells. Luc-LM8 cells were incubated with parthenolide ( 0 and $1.0 \mu \mathrm{g} / \mathrm{ml}$ ) for $24 \mathrm{~h}$, and then irradiated with $0,2,4$ and $6 \mathrm{~Gy}, 180 \mathrm{kVp} \mathrm{X}$-rays. At $72 \mathrm{~h}$ after irradiation, medium was replaced with that containing WST-1 reagent, and $3 \mathrm{~h}$ later, the absorbance was determined at $450 \mathrm{~nm}$. Relative change in cell viability was represented as the ratio of the absorbance of viable cells vs. the control (no parthenolide and no irradiation treatment) group, which was standardized as $100 \%$ (mean $\pm \mathrm{SD}, \mathrm{n}=3$; " $\mathrm{P}<0.05$ ). Irradiation significantly inhibited the growth of Luc-LM8 cells. Although parthenolide (Par) alone did not alter cell growth, parthenolide significantly enhanced the growth inhibitory effect of irradiation at every dose tested.

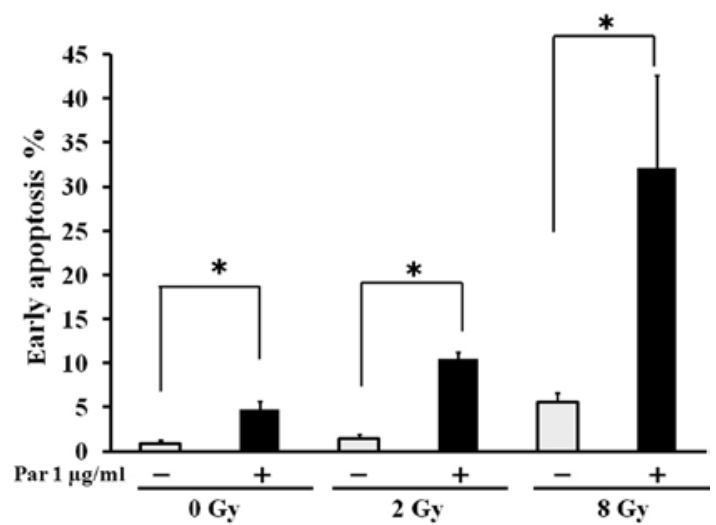

Figure 4. Parthenolide enhances irradiation-induced apoptosis of Luc-LM8 cells. Luc-LM8 cells $\left(1 \times 10^{4}, 12\right.$-well plate) were incubated with parthenolide $(0$ and $1.0 \mu \mathrm{g} / \mathrm{ml})$ for $24 \mathrm{~h}$, and irradiated with 0,2 and $8 \mathrm{~Gy}, 180 \mathrm{kVp} \mathrm{X}$-rays. At $48 \mathrm{~h}$ after irradiation, cells were incubated with Annexin $\mathrm{V}$ reagent, and the degree of apoptosis was assessed by a FACSCaliber flow cytometer. Treatment with parthenolide alone induced apoptosis of Luc-LM8 cells by a small but significant degree (mean $\pm \mathrm{SD}, \mathrm{n}=3$; ${ }^{*} \mathrm{P}<0.05$ ). However, irradiation markedly induced apoptosis of Luc-LM8 cells treated by parthenolide in a synergistic manner.

Parthenolide enhanced irradiation-induced growth inhibition and apoptosis of Luc-LM8 cells in vitro. In the in vitro proliferation assay, irradiation significantly inhibited the growth of Luc-LM8 cells. Although parthenolide alone did not alter cell growth, we found that parthenolide significantly enhanced the growth inhibitory effect of RT at every dose tested (Fig. 3). Furthermore, in the apoptosis detection assay, irradiation markedly induced apoptosis of Luc-LM8 cells treated with parthenolide in vitro in a synergistic manner (Fig. 4). These results suggest that parthenolide sensitized Luc-LM8 cells to irradiation, most likely through the inhibition of the NF- $\mathrm{kB}$.

Parthenolide suppressed NF- $\kappa$ B transcriptional activity of the Luc-LM8 tumors and sensitized the tumors to irradiation. To

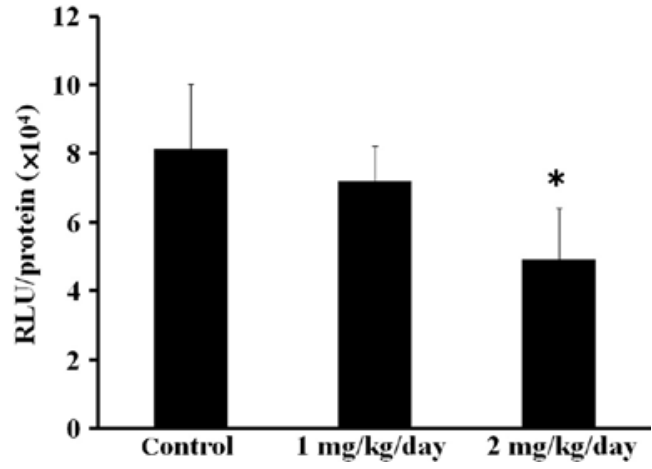

Figure 5. Parthenolide suppresses NF- $\mathrm{KB}$ transcriptional activity of the Luc-LM8 tumors in vivo. NF- $\kappa \mathrm{B}$ activity in the tumors was inhibited by parthenolide in a dose-dependent manner. The NF- $\kappa B$ activity of the 2-mg group was significantly suppressed compared with the control group (mean $\pm \mathrm{SD},{ }^{*} \mathrm{P}<0.05$ vs. control)

investigate whether our in vitro findings of a radio-sensitization effect were also true for osteosarcoma in vivo, we conducted animal experiments using a mouse model of s.c. tumor cell inoculation. In the tumor homogenate-based luciferase assay, the NF- $\mathrm{KB}$ transcriptional activity in the primary tumors was inhibited by parthenolide in a dose-dependent manner (Fig. 5). The NF- $\mathrm{KB}$ activity of the $2 \mathrm{mg} / \mathrm{kg} /$ day parthenolide group was significantly suppressed compared with the control group.

In the tumor growth assay, we found that tumor growth was significantly suppressed in the Par+RT group compared to all other groups. No other significant differences were observed among the groups. These findings indicate the synergistic effect of Par and RT on tumor growth inhibition (Fig. 6A and B). In addition, histological analysis revealed the necrotic change in tumor tissue in all of the experimental groups (Fig. 6C), and the degenerative area was more extensive in the Par+RT group. These findings suggest that parthenolide has a radio-sensitizing potential on Luc-LM8 osteosarcoma in vivo.

\section{Discussion}

In the present study, we showed the radio-sensitizing properties of parthenolide in vitro and in vivo in Luc-LM8, a transfectant with pNF-кB-Luc into a highly metastatic murine osteosarcoma cell line, LM8. Radio-sensitization achieved by inhibition of NF- $\mathrm{KB}$ was previously shown with similar effects in different types of cancer in vitro and in vivo $(4,22-25)$. The majority of in vivo antitumor studies on the inhibition of NF- $\mathrm{KB}$ activity used gene therapy, including the overexpression of the I $\mathrm{B}$ mutant that promotes the ubiquitine-proteasome degradation of NF-KB. Eliseev et al (26) suggested that in the osteosarcoma cell line, Saos2, inhibiting NF- $\kappa \mathrm{B}$ activity by expressing the I $\mathrm{B}$ mutant induces radiosensitization and intrinsic apoptosis after ionizing radiation. Studies have shown the antitumor radio-sensitizing activity of parthenolide in vitro. Mondonca et al (27) found that parthenolide enhanced X-ray-induced cell killing in radiationresistant, NF-kB-activated CGL1 cells due to inhibition of split-dose repair. Sun et al (28) showed that the radio-sensitization effect of parthenolide in prostate cancer cells was mediated by NF- $\kappa \mathrm{B}$ inhibition and enhanced by the presence of PTEN. However, the in vivo radio-sensitizing activity of 
A

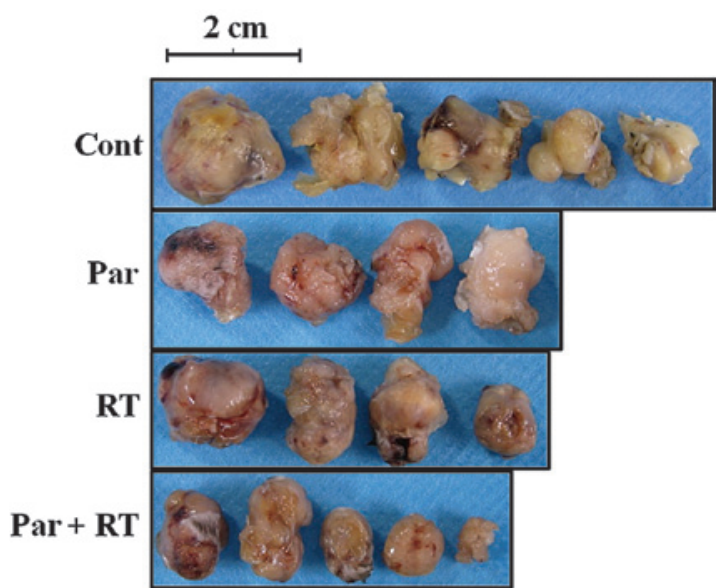

B
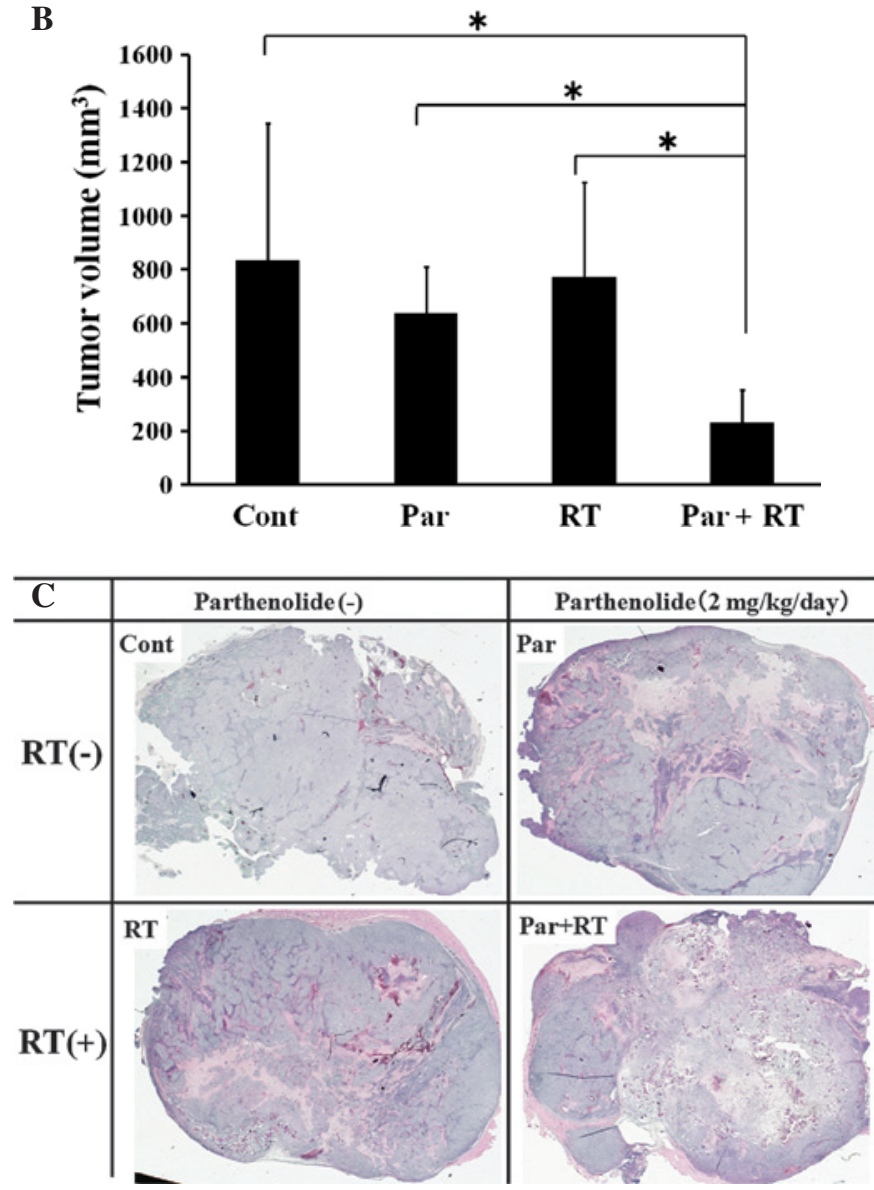

Figure 6. Parthenolide sensitizes Luc-LM8 tumors to irradiation. (A) In gross appearance, the relative tumor size of the Par+RT group was smaller than that of the other groups. (B) Tumor volume was significantly suppressed in the Par+RT group when compared to the control (Cont) group, but not when compared with the other groups (mean $\pm \mathrm{SD}, \mathrm{n}=4-5$; $^{*} \mathrm{P}<0.05$ ). (C) In the histological analysis, tissue degeneration was found in all experimental groups, and the degenerative area was more extensive in the Par+RT group.

parthenolide has yet to be elucidated. In a previous study, we showed that parthenolide effectively blocked the development of lung metastasis of LM8 (29). Parthenolide is currently used commonly as a food supplement for the treatment of migraines and reportedly was found to have no severe side effects when compared with the placebo group. Therefore, it may be more effective than gene therapy in vivo (30).
In our in vitro study, we investigated the radio-sensitization effects of parthenolide on Luc-LM8 cells. First, we showed that the NF- $\kappa \mathrm{B}$ transcriptional activity in Luc-LM8 cells was inhibited by parthenolide in a dose-dependent manner. Then, in the proliferation assay, parthenolide significantly enhanced the growth inhibitory effect of radiation therapy at every dose tested. These results indicate that parthenolide increases the radio-sensitivity of Luc-LM8 cells. We hypothesized that this radio-sensitization effect of parthenolide was due to an apoptotic response exerted via inhibition of the NF- $\mathrm{KB}$ pathway. To test this hypothesis, we assessed early apoptotic reactions in Luc-LM8 cells treated with parthenolide and irradiation. In the apoptosis detection assay, parthenolide induced apoptosis of Luc-LM8 cells, and the cell apoptosis rate synergistically increased in a dose-dependent manner with irradiation. Our findings suggest that parthenolide induces an apoptotic response exerted via inhibition of the NF- $\kappa \mathrm{B}$ pathway and increases the radio-sensitivity of Luc-LM8 cells, and accordingly inhibits the proliferation of Luc-LM8 cells.

In the in vivo s.c. tumor model, the tissue homogenatebased luciferase assay revealed that 7 days of parthenolide injection reduced the $\mathrm{NF}-\kappa \mathrm{B}$ activity in Luc-LM8 tumor tissue on the day of irradiation (day 14) in a dose-dependent manner. Furthermore, our in vivo tumor growth study showed that 14 days after irradiation, tumor growth was significantly suppressed in the parthenolide-treated group compared with the control group. Histologically, necrotic changes in tumor tissue were found in all experimental groups and the area of necrosis was more extensive in the irradiation with parthenolide group. Thus, it appears that parthenolide has the potential to enhance the necrotizing effect of irradiation on in vivo tumor masses.

Parthenolide has been reported to have microtubuleinterfering properties (31) that induce apoptotic cell death by multiple pathways, including oxidative stress, endoplasmic reticulum stress, intracellular thiol depletion, caspase activation, and mitochondrial dysfunction $(15,17,18)$, inhibit 5-lipoxygenase and cyclooxygenase (32) and sensitize cancer cells to chemotherapeutic drugs such as paclitaxel and docetaxel $(33,34)$. Despite widely documented anti-cancer activity and the absence of major adverse effects, clinical development of parthenolide is hampered by its poor water solubility, (35) thus limiting its potential as a promising clinical agent. Previous studies investigated the in vitro and in vivo activities of the water-soluble parthenolide analogue dimethylaminoparthenolide (DMAPT) $(20,35,36)$ and reported that this analogue suppressed tumor growth by targeting $\mathrm{NF}-\kappa \mathrm{B}$ and generating reactive oxygen (37-39). The water-soluble parthenolide analogue may become a more readily available radio-sensitizing agent, but further investigation is needed to elucidate its efficacy and spectrum as a radio-sensitizing agent.

In the present study, parthenolide suppressed Luc-LM8 cell growth, induced apoptosis in vitro, and inhibited tumor growth in vivo synergistically with irradiation treatment, suggesting that parthenolide sensitizes Luc-LM8 to irradiation. It is conceivable that the mechanism of radio-sensitization may be the inhibition of NF- $\kappa$ B activity since NF- $\kappa$ B has been shown to be associated with cancer resistance to RT. Parthenolide is a potential candidate for use as a potent radio-sensitizing drug for use in cancer RT. 


\section{Acknowledgements}

This study was supported by a Grant-in-Aid for Scientific Research (no. 20591754) from the Ministry of Education, Culture, Sports, Science and Technology, Japan grants. We also would like to thank Dr Satoaki Nakamura for the invaluable advice and Mrs. Mari Shinkawa for the excellent technical assistance in the histological study.

\section{References}

1. Unni KK: Osteosarcoma of bone. J Orthop Sci 3: 287-294, 1998.

2. Fuchs B and Pritchard DJ: Etiology of osteosarcoma. Clin Orthop Relat Res: 40-52, 2002.

3. Bernier J, Hall EJ and Giaccia A: Radiation oncology: a century of achievements. Nat Rev Cancer 4: 737-747, 2004.

4. Jung $M$ and Dritschilo A: NF-kappaB signaling pathway as a target for human tumor radiosensitization. Semin Radiat Oncol 11: 346-351, 2001.

5. Habraken Y and Piette J: NF-kappaB activation by double-strand breaks. Biochem Pharmacol 72: 1132-1141, 2006.

6. McKenna WG and Muschel RJ: Targeting tumor cells by enhancing radiation sensitivity. Genes Chromosomes Cancer 38: 330-338, 2003.

7. Kim HJ, Hawke $\mathrm{N}$ and Baldwin AS: NF-kappaB and IKK as therapeutic targets in cancer. Cell Death Differ 13: 738-747, 2006.

8. Nakanishi $\mathrm{C}$ and Toi M: Nuclear factor-kappaB inhibitors as sensitizers to anticancer drugs. Nat Rev Cancer 5: 297-309, 2005.

9. Asai T, Tomita Y, Nakatsuka S, et al: VCP (p97) regulates NFkappaB signaling pathway, which is important for metastasis of osteosarcoma cell line. Jpn J Cancer Res 93: 296-304, 2002.

10. Asai T, Ueda T, Itoh K, et al: Establishment and characterization of a murine osteosarcoma cell line (LM8) with high metastatic potential to the lung. Int J Cancer 76: 418-422, 1998.

11. Knight DW: Feverfew: chemistry and biological activity. Nat Prod Rep 12: 271-276, 1995.

12. Liu CA, Wang MJ, Chi $\mathrm{CW}, \mathrm{Wu} \mathrm{CW}$ and Chen JY: Rho/ Rhotekin-mediated NF-kappaB activation confers resistance to apoptosis. Oncogene 23: 8731-8742, 2004.

13. Shanmugam R, Jayaprakasan V, Gokmen-Polar Y, et al: Restoring chemotherapy and hormone therapy sensitivity by parthenolide in a xenograft hormone refractory prostate cancer model. Prostate 66: 1498-1511, 2006.

14. Zhang S, Won YK, Ong CN and Shen HM: Anti-cancer potential of sesquiterpene lactones: bioactivity and molecular mechanisms. Curr Med Chem Anticancer Agents 5: 239-249, 2005.

15. Koprowska K and Czyz M: [Molecular mechanisms of parthenolide's action: old drug with a new face]. Postepy Hig Med Dosw (Online) 64: 100-114, 2010 (In Polish).

16. Oka D, Nishimura K, Shiba M, et al: Sesquiterpene lactone parthenolide suppresses tumor growth in a xenograft model of renal cell carcinoma by inhibiting the activation of NF-kappaB. Int J Cancer 120: 2576-2581, 2007.

17. Wen J, You KR, Lee SY, Song CH and Kim DG: Oxidative stress-mediated apoptosis. The anticancer effect of the sesquiterpene lactone parthenolide. J Biol Chem 277: 38954-38964, 2002.

18. Zhang S, Ong CN and Shen HM: Critical roles of intracellular thiols and calcium in parthenolide-induced apoptosis in human colorectal cancer cells. Cancer Lett 208: 143-153, 2004.

19. Kim JH, Liu L, Lee SO, Kim YT, You KR and Kim DG: Susceptibility of cholangiocarcinoma cells to parthenolideinduced apoptosis. Cancer Res 65: 6312-6320, 2005.

20. Guzman ML, Rossi RM, Karnischky L, et al: The sesquiterpene lactone parthenolide induces apoptosis of human acute myelogenous leukemia stem and progenitor cells. Blood 105: 4163-4169, 2005.

21. Griesenbach U, Meng C, Farley R, et al: In vivo imaging of gene transfer to the respiratory tract. Biomaterials 29: 1533-1540, 2008.
22. Wang CY, Mayo MW and Baldwin AS Jr: TNF- and cancer therapy-induced apoptosis: potentiation by inhibition of NF-kappaB Science 274: 784-787, 1996.

23. Mukogawa T, Koyama F, Tachibana M, et al: Adenovirusmediated gene transduction of truncated IkappaBalpha enhances radiosensitivity in human colon cancer cells. Cancer Sci 94: 745-750, 2003 .

24. Magne N, Toillon RA, Bottero V, et al: NF-kappaB modulation and ionizing radiation: mechanisms and future directions for cancer treatment. Cancer Lett 231: 158-168, 2006.

25. Mauro C, Zazzeroni F, Papa S, Bubici C and Franzoso G: The NF-kappaB transcription factor pathway as a therapeutic target in cancer: methods for detection of NF-kappaB activity. Methods Mol Biol 512: 169-207, 2009.

26. Eliseev RA, Zuscik MJ, Schwarz EM, O'Keefe RJ, Drissi H and Rosier RN: Increased radiation-induced apoptosis of Saos 2 cells via inhibition of NF-kappaB: a role for c-Jun N-terminal kinase. J Cell Biochem 96: 1262-1273, 2005.

27. Mendonca MS, Chin-Sinex H, Gomez-Millan J, et al: Parthenolide sensitizes cells to X-ray-induced cell killing through inhibition of NF-kappaB and split-dose repair. Radiat Res 168: 689-697, 2007.

28. Sun Y, St. Clair DK, Fang F, et al: The radiosensitization effect of parthenolide in prostate cancer cells is mediated by nuclear factor-kappaB inhibition and enhanced by the presence of PTEN. Mol Cancer Ther 6: 2477-2486, 2007.

29. Kishida Y, Yoshikawa H and Myoui A: Parthenolide, a natural inhibitor of nuclear factor-kappaB, inhibits lung colonization of murine osteosarcoma cells. Clin Cancer Res 13: 59-67, 2007.

30. Murphy JJ, Heptinstall S and Mitchell JR: Randomised doubleblind placebo-controlled trial of feverfew in migraine prevention. Lancet 2: 189-192, 1988.

31. Miglietta A, Bozzo F, Gabriel L and Bocca C: Microtubuleinterfering activity of parthenolide. Chem Biol Interact 149: $165-173,2004$.

32. Sumner H, Salan U, Knight DW and Hoult JR: Inhibition of 5-lipoxygenase and cyclooxygenase in leukocytes by feverfew. Involvement of sesquiterpene lactones and other components. Biochem Pharmacol 43: 2313-2320, 1992.

33. Patel NM, Nozaki S, Shortle NH, et al: Paclitaxel sensitivity of breast cancer cells with constitutively active NF-kappaB is enhanced by IkappaBalpha super-repressor and parthenolide. Oncogene 19: 4159-4169, 2000.

34. Sweeney CJ, Mehrotra S, Sadaria MR, et al: The sesquiterpene lactone parthenolide in combination with docetaxel reduces metastasis and improves survival in a xenograft model of breast cancer. Mol Cancer Ther 4: 1004-1012, 2005.

35. Neelakantan S, Nasim S, Guzman ML, Jordan CT and Crooks PA: Aminoparthenolides as novel anti-leukemic agents: discovery of the NF-kappaB inhibitor, DMAPT (LC-1). Bioorg Med Chem Lett 19: 4346-4349, 2009.

36. Guzman ML, Rossi RM, Neelakantan S, et al: An orally bioavailable parthenolide analog selectively eradicates acute myelogenous leukemia stem and progenitor cells. Blood 110: 4427-4435, 2007.

37. Shanmugam R, Kusumanchi P, Cheng L, et al: A water-soluble parthenolide analogue suppresses in vivo prostate cancer growth by targeting NF-kappaB and generating reactive oxygen species. Prostate 70: 1074-1086, 2010.

38. Shanmugam R, Kusumanchi P, Appaiah H, et al: A water soluble parthenolide analog suppresses in vivo tumor growth of two tobacco-associated cancers, lung and bladder cancer, by targeting NF-kappaB and generating reactive oxygen species. Int J Cancer: July 28, 2010 (Epub ahead of print).

39. Yip-Schneider MT, Wu H, Ralstin M, et al: Suppression of pancreatic tumor growth by combination chemotherapy with sulindac and LC-1 is associated with cyclin D1 inhibition in vivo. Mol Cancer Ther 6: 1736-1744, 2007. 